Sociológico

Forum Sociológico

Série II

31 | 2017

Transition to work of graduates in Southern Europe:

Crisis and new challenges

\title{
Lista de referes - Números 28, 29, 30 e 31
}

\section{(2) OpenEdition \\ Journals}

Edição electrónica

URL: https://journals.openedition.org/sociologico/1850

DOI: 10.4000/sociologico.1850

ISSN: 2182-7427

Editora

CICS.NOVA - Centro Interdisciplinar de Ciências Sociais da Universidade Nova de Lisboa

Edição impressa

Paginação: 91

ISSN: 0872-8380

Refêrencia eletrónica

«Lista de referes - Números 28, 29, 30 e 31 », Forum Sociológico [Online], 31 | 2017, posto online no dia

31 dezembro 2017, consultado o 31 março 2022. URL: http://journals.openedition.org/sociologico/

1850 ; DOI: https://doi.org/10.4000/sociologico.1850

(c) CICS.NOVA 


\section{EDITORIAL}

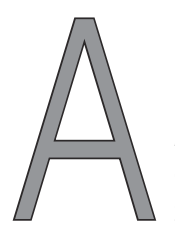

Forum Sociológico mantem neste número o formato que melhor a tem caracterizado nos últimos anos: a um dossiê temático neste caso intitulado "Transition to work of graduates in Southern Europe: crisis and new challenges", que agrega a maioria dos textos, vêm somar-se três valiosos contributos autónomos. Da sociologia à antropologia, da economia à arquitetura, deparamos, uma vez mais, nesta edição, com autores de diversas áreas de formação que vêm contribuir, com as suas análises, para o enriquecimento interdisciplinar das ciências sociais, em especial da sociologia.

Coordenado por Miguel Chaves e Mariana Gaio Alves, professores respetivamente da Faculdade de Ciências Sociais e Humanas (FCSH) e da Faculdade de Ciência e Tecnologia (FCT), ambas escolas da Universidade Nova de Lisboa (UNL), o dossiê reúne textos produzidos na sequência do seminário "Employability of Higher Education Graduates in Southern Europe: crisis and new challenges", realizado em finais de novembro de 2016 na Sala do Senado da Reitoria da UNL.

O tema, claramente explicitado no título, tem merecido crescente visibilidade nas agendas política e mediática. As razões para essa atenção são várias, avultando as que decorrem do aprofundamento das sociedades do conhecimento, com o concomitante reconhecimento do papel da educação e da formação para o desenvolvimento económico e para o reforço da coesão social e da democracia. O número crescente de indivíduos que após completarem este nível de formação se procuram inscrever no mercado de trabalho em situações de sobrequalificação, precaridade e desemprego é também um motivo que justifica a atenção, embora o destaque que lhe é conferido seja por vezes exagerado, atreito a sensacionalismo mediático, sobretudo se comparamos a situação dos jovens diplomados com a dos congéneres que não completaram o ensino superior.

No contexto europeu, o desemprego e a precaridade registados junto desta população parecem assumir especial significado nos países do sul. É nesses casos que a crise financeira irá assumir proporções mais agudas, a ponto de, em diversos casos, ter dado lugar à assunção de programas de assistência financeira, conduzidos, em anos recentes, pela Comissão Europeia (CE), o Banco Central
Europeu (BCE) e o Fundo Monetário Internacional (FMI). As políticas de austeridade implementadas ou reforçadas no âmbito desses mecanismos de "resgate" originaram e intensificaram cenários de crise económica, caracterizados, entre outros aspetos, por reduções no investimento público e privado, que aumentaram, pelo menos no médio prazo, o fosso entre as economias da UE, em contradição com o proclamado ideal de convergência.

Importa, portanto, interrogar: terão os jovens diplomados sido atingidos com a mesma intensidade com que o foram as demais populações juvenis? $\mathrm{E}$, independentemente disso, terão mantido certas prerrogativas de maior proteção face ao desemprego e à insegurança do emprego de que usufruíam, em termos relativos, antes da eclosão da crise?

Incorporando contributos de investigadores portugueses, espanhóis, italianos e gregos, o dossiê procura promover uma análise profunda, assente em dados empíricos robustos e atualizados, extraídos de diversas fontes nacionais e internacionais, da situação de inserção profissional dos recém graduados nos quatro países de que os investigadores são originários, escalpelizando o modo com esta evoluiu desde 2000 .

Pretende-se assim que o leitor fique em condições de identificar similaridades e diferenças entre os vários países, fomentando uma visão de conjunto da inserção de diplomados no sul da Europa. Adicionalmente, embora com menos ênfase, alguns dos textos procuram também dar a conhecer algumas políticas públicas que, direta ou indiretamente, pretendem facilitar e promover a empregabilidade de diplomados nos países em análise.

Em termos gerais, foi possível aos coordenadores do dossier, tecer uma visão de síntese, reforçada, mais tarde, com recurso aos dados do EUROSTAT. Em primeiro lugar, a evolução dos indicadores é similar em Portugal, Grécia, Itália e Espanha. Em segundo lugar, à semelhança do que sucede em outras matérias, também por domínio de emprego de jovens diplomados, a média europeia não acompanha os "PIGS". Enquanto os resultados dos quatro países do fundo do mapa se afundam ininterrupta e dramaticamente num "ajustamento" sem fim ou estabilizam, provisoriamente, em níveis medíocres, a média europeia mantém-se ou sofre oscilações pouco sensíveis, mesmo incluindo já os resultados dos quatro países em análise. 
A relevância internacional deste tema, associada à dificuldade de se encontrar compilações de textos que sobre ele reflitam, levou a que se tivesse optado por manter, não sem hesitações, os textos na sua versão em língua inglesa, em detrimento de os submeter a um exercício de tradução. Garante-se assim que possam circular de forma mais alargada, sobretudo na versão online.

$\mathrm{O}$ artigo centrado na realidade portuguesa, intitulado "Employability of higher education graduates in Portugal: trends and challenges in the beginning of the 21st century", abre a coletânea de artigos. A partir de uma extensa análise de dados estatísticos, o texto procura analisar as principais tendências registadas no emprego dos diplomados portugueses, desde o início do Séc. XXI, ao mesmo tempo que pontua o conjunto complexo de fatores que enquadra o processo de transição educação-trabalho.

Num país em que o número de graduados tem vindo a aumentar, embora mantendo-se longe do horizonte estabelecido pela UE para 2020, os autores mostram-nos que a situação dos diplomados portugueses face ao mercado de trabalho sofreu uma deterioração desde os primeiros anos do século, visível na redução das taxas de atividade e no decréscimo das remunerações médias. Demonstram-nos ainda que a situação se agravou rapidamente a partir de 2010, e que recuperou nos últimos dois anos, embora mantendo-se a uma considerável distância do cenário registado no início do século. Revelam-nos, por fim, que os indicadores de precariedade contratual e a incidência da emigração são comparativamente altos, em Portugal. Apenas o ajustamento do nível de instrução às atividades profissionais parece superar positivamente as médias europeias.

Na sequência destas observações, os autores chamam a atenção para a necessidade de se desenharem políticas nacionais e europeias destinadas a ultrapassar este cenário deteriorado, pois se é indubitável que os diplomas continuam, mesmo nas faixas etárias de diplomados mais recentes, a constituir uma vantagem perante o mercado de trabalho, não são suficientes para garantir proteção contra o desemprego.

Parte das reflexões a propósito de Portugal são partilhadas no segundo artigo, da autoria de Juan-Ignacio Martínez-Pastor, que analisa o emprego dos diplomados espanhóis, quer em quantidade, quer em qualidade. Martínez-Pastor conclui que tanto nos períodos de crise como de bonança, registados desde 2000 , os diplomados se encontram mais protegidos contra o desemprego, avançando que tal se deve sobretudo ao facto de esses diplomados trabalharem em setores e ocupações menos expostos a ciclos. Os diplomados parecem também estar menos confrontados com contratos a termo, embora as suas vantagens não sejam, nesse capítulo, significativamente maiores do que as dos trabalhadores que obtiveram formação profissional ou que realizaram todo o ensino secundário. As vantagens remuneratórias dos indivíduos com o ensino superior são também evidentes, declinando porém em termos relativos, ao longo do tempo, em parte porque tem vindo a aumentar o número de diplomados empregados em atividades desenquadradas do seu nível educacional.

Michele Rostan e Adriana Stan guiam-nos, por seu turno, a Itália, começando por nos revelar, de forma algo surpreendente, que neste país o número de matriculados no ensino superior e de diplomados se manteve relativamente baixo quando comparado com as médias da OCDE, não se registando, além disso, o crescimento acentuado verificado noutros países, entre os quais Portugal. Tal situação agravou-se mais ainda com a crise, em contraste com os objetivos definidos na reforma universitária de 1999.

Cruzando, de seguida, dados provenientes de diversas fontes, os autores tornam patente que a crise económica teve um forte impacto no mercado de trabalho, observável na contração da percentagem de empregados, que afetou claramente os jovens diplomados. Essa situação parece ter afetado sobretudo os indivíduos que concluíram o $1 .^{\circ}$ ciclo, uma vez que aqueles que finalizaram o $2 .{ }^{\circ}$ ciclo viram a sua situação relativamente inalterada, em parte porque já se encontravam a trabalhar aquando da intensificação da crise.

No entanto, para Michele Rostan e Adriana Stan a crise não fez senão aumentar certos traços negativos do mercado de trabalho para graduados em Itália, que são, em seu entender, persistentes. Comparando essa situação com a vivida na Alemanha, apresentada como liderante no espaço europeu, avançam três leituras explicativas para esse facto - o défice do sistema produtivo, em especial a sua reduzida capacidade para criar empregos para diplomados; a baixa diversificação da estrutura de educação terciária, polarizada pelas universidades e com débil presença da formação não-universitária de cariz profissionalizante; por fim, os problemas de comunicação e articulação entre educação e economia.

Em quarto lugar, surge o texto "Degrees of precariousness: the problematic transition into the labour market of Greek higher education graduates". A propósito do país onde a crise económica se fez sentir de forma mais devastadora, Spyros Themelis analisa o processo de inserção profissional dos diplomados gregos, identificando três dos elementos centrais desse processo, a saber, o adiamento e o caráter nunca completado do processo de transição desses diplomados para o mercado de trabalho; a diversificação interna do recrutamento para esse mercado, em função de aspetos que, além do nível de educação, incluem também o lugar de residência, género, idade e origem étnica; a circunstância de a educação superior não parecer assumir um papel 
claramente integrador dos indivíduos no mundo laboral, uma vez que não oferece garantias contra o desemprego, a precariedade e a emigração.

Por intermédio do enorme estreitamento dos horizontes de trabalho dos sectores público e privado, a crise veio reforçar qualquer dos problemas do mercado de trabalho, assim como os défices da sua conexão com a educação superior. A emigração, solução encontrada pelos jovens gregos para o estrangulamento dos horizontes de trabalho e das suas expectativas, corresponde a uma série ameaça à recuperação económica nesse país, em virtude de potenciar, tal como em Portugal, uma perda dos recursos humanos mais qualificados, absorvidos pelas nações do centro europeu. Tal como refere Themelis, de forma sintética mas esclarecedora, no início do texto, "os problemas múltiplos e sobrepostos que subjazem à transição do ensino superior para o mercado de trabalho está no cerne dos problemas econômicos e políticos que a Grécia enfrenta e apontam como que para existência de uma bomba-relógio nas fundações da sociedade grega".

Finalizado o dossiê, este número da Forum conta ainda com três contributos relevantes.

Em primeiro lugar, a antropóloga Sílvia Raposo centra-se na obra escultórica de Gonçalo Mabunda e Hilario Nhatugueja, mostrando-nos como a partir de uma "reciclagem" e reprodução dos ícones de guerra, nomeadamente armamento, a obra destes artistas moçambicanos faculta a possibilidade de se rearquitetarem significados e mnemónicas associadas à guerra civil moçambicana, num claro exemplo de como a linguagem artística pode assumir um papel performativo, criador de tensões, dissensos e dissidências com um eminente conteúdo contra hegemónico, na medida em que torna as memórias plurais, resgatando-as à memorialia oficial.

De seguida, somos conduzidos por Ricardo Roque à análise da ação político-sanitária que Bissaya Barreto desenvolveu durante o Estado Novo, no território português da Beira Litoral. O autor dá um importante contributo para esclarecer como a arquitetura se constituiu com um vetor central de higienização e de cura no âmbito do projeto desenvolvido por este médico com marcada inspiração maçónica.

O número da Forum culmina com a apresentação de um documento que sintetiza os apetos dominantes debatidos num seminário que a Fundação Friedrich Ebert em conjunto com a European Alternatives organizaram já este ano acerca da situação dos refugiados e das organizações que os apoiam em Portugal. Além de nos documentar acerca do modo como está a ser tratado um tema que tem ganho especial relevância na sequência de desenvolvimentos dramáticos no momento presente, este relatório, elaborado por Vicente Valentim, Inês Vieira e Christine Auer, pretende estimular a reflexividade e o trabalho voluntário orientados para este domínio de estudo e intervenção.

Fecha-se assim um número da Forum Sociológico onde, uma vez mais, se procura garantir que a análise sociológica e a relevância social se articulam de forma crítica.

Miguel Chaves e Mariana Gaio Alves 